\title{
Control surface design for radio-controlled aircraft. Case: SAE aero design micro-class prototype
}

\author{
Diseño de superficies de control para aeronaves radiocontroladas. Caso: prototipo clase \\ micro SAE aero design \\ Rafael A. Márquez (D) ${ }^{1}$, Miguel A. Martínez (iD) ${ }^{1}$, Manuel J. Martínez (iD) 2 \\ ${ }^{1}$ Facultad de Ingeniería, Universidad Metropolitana. Av. Boyacá con autopista Petare-Guarenas. Urbanización Terrazas \\ del Ávila. C. P. 1073. Caracas, Venezuela. \\ ${ }^{2}$ Facultad de Ingeniería y Tecnología, Universidad San Sebastián. Gral. Lagos 1163. C. P. 5090000. Valdivia, Chile.
}

\section{CITE THIS ARTICLE AS:}

\author{
R. A. Márquez, M. A. Martínez \\ and M. J. Martínez. "Control \\ surface design for \\ radio-controlled aircraft. \\ Case: SAE Aero Design \\ Micro-class prototype", Revista \\ Facultad de Ingeniería \\ Universidad de Antioquia, no. \\ 104, pp. 71-82, Jul-Sep 2022. \\ [Online]. Available: https: \\ //www.doi.org/10.17533/ \\ udea.redin. 20210740
}

\section{ARTICLE INF0:}

Received: January 26, 2021 Accepted: July 26, 2021

Available online: July 27, 2021

\section{KEYWORDS:}

Aircraft; aerodynamics; XFLR5; design methodology; fluid dynamics

Aeronave; aerodinámica; XFLR5; metodología de diseño; dinámica de fluidos
ABSTRACT: This research article presents a design methodology for primary control surfaces (Ailerons, Rudder and Elevator) for experimental unmanned radio-controlled aircraft. The methodology is based on the proposal and standardization of the required mechanical and aerodynamic analysis for each control surface sizing, considering the SAE Aero Design competition objectives within Micro Class. It is used on empirical results previously described in references about aeronautical design, computerized fluids dynamics (CFD) software, and aircraft controllability regulations in order to obtain the design variables. Based on this information, the iteration sequences required for design were automated by a $\mathrm{C}_{++}$language code to obtain the optimal characteristics for each surface, thereby reducing the possibility of calculation errors, overall time, and workload invested in the design process. The application of the methodology to the latest aircraft design reduced the total control systems weight to the aircraft's empty weight ratio to a minimum of $3.4 \%$.

RESUMEN: Se presenta una metodología para el diseño de superficies de control primarias, alerones, timón de dirección y elevador, en aeromodelos experimentales radiocontrolados. La metodología se basa en la propuesta y estandarización de los análisis mecánicos y aerodinámicos requeridos para el dimensionamiento de cada superficie de control, en función de los objetivos de la competencia SAE (Society of Automotive Engineers) Aero Design en su categoría Micro. Para ello fue necesaria la obtención de las variables de diseño a partir de resultados empíricos previamente descritos en la bibliografía sobre diseño aeronáutico, así como del empleo de programas de dinámica de fluidos computacional y de los estándares que regulan la controlabilidad de las aeronaves. La secuencia de iteraciones necesarias en el diseño se automatizó por medio de un código escrito en lenguaje $\mathrm{C}++$ con la finalidad de obtener las variables de diseño óptimas de cada superficie, reduciendo posibles errores de cálculo y el tiempo invertido en el proceso de diseño. La aplicación de la metodología al último diseño construido ayudó a disminuir la relación entre el peso total de los sistemas de control respecto al peso en vacío de la aeronave a un mínimo de 3,4\%.

\section{Introduction}

The SAE Aero Design competition is intended to provide engineering students with real-life challenges, posing the

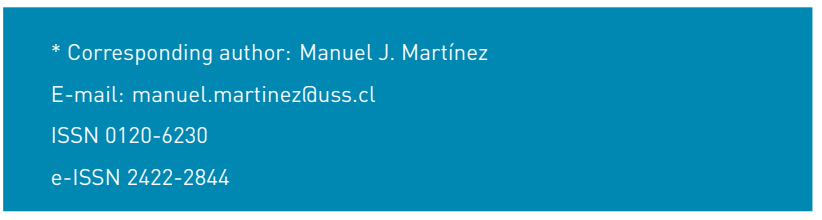

kind of problems that engineers must address in the work environment [1]. Thus, the participation in the Micro category of the competition is aimed at the design of a micro-UAV (unmanned aerial vehicle) of low weight, which can be assembled in the shortest time possible and deployed manually, carrying the greatest amount of cargo in relation to its unladen weight [2]. The design and construction of unmanned aircraft evolve depending on the needs of users and their expectations: universities, government agencies, technology companies, public and 
private research and development centers, mostly, carry out research according to their interests [3]. Moreover, other report shows that UAVs are used in other applications such as precision agriculture and mapping [4]. Therefore, the design of the competition's Micro category aircraft must consider proper control and ease of maneuvering, so as to avoid forced landings or partial or total loss of the aircraft. A poor design of the aircraft control surfaces means that the aircraft does not meet the requirements of the competition.

The aircraft design is a collaborative and multidisciplinary process. It involves several experts with different disciplinary competences that often belong to different departments or organizations, such as developing a new generation of multidisciplinary design analysis and optimization (MDAO) frameworks for aircraft design [5]. The design of an aircraft goes through an initial phase of conceptual design in which the requirements requested by customers are considered: technological level, size of the aircraft, appropriate engines, airworthiness; comprehensive solutions in the form of schemes where aspects such as practical knowledge, production methods, and commercial scope have great relevance $[6,7]$. The design of an aircraft is a complex process that considers different disciplines holistically: safety requirements, reliability goals, performance specifications required by the mission to be fulfilled, among others [8]. For example, after establishing the preliminary design of the aircraft, stability is analyzed, and control surfaces are designed [9]. In the design of control surfaces, two aspects are particularly relevant, their dimensioning and the associated control laws. These aspects can be approached through optimization strategies. Regarding the design of control surfaces, through the application of an optimization process in the airfoils of a BWB, blended wing body configuration, an improvement in aerodynamic performance is obtained in a transonic regime [10]. Regarding optimization techniques, plant-controller optimization problems can be solved by sequential, iterative and simultaneous strategies, the latter being the one that guarantees optimal results due to the coupling of the fields [11]. Consequently, the dimensioning of control surfaces and the design of the corresponding control laws constitute a coupling problem, whose resolution can be approximated by techniques such as multidisciplinary optimization (MDO) or linear matrix inequalities (LMI), among others [12]. In obtaining the control variables and calculating the dynamic stability a CFD modeling by means of the panel method is proposed highlighting the importance of computer modeling to complement the results of experimental tests, such as wind tunnel testing [13]. The use of wind tunnels occurs in the last phases of the design. For example, the evaluation of the different aerodynamic behavior of a low aspect ratio wing at high angles of deflection by means of an experimental wind tunnel test campaign on a generic regional turboprop aircraft model with a modular vertical tail with a rudder [14]. However, sometimes, the quality of the air flow may affect the aerodynamic performance $[15,16]$. With the increase of the computer's calculation capacity, in terms of memory, and speed, the programs have evolved in complexity, efficiency and precision of their results. Although programs based on numerical methodologies can be time-consuming in the development of simulations, they provide increasingly accurate results. For instance, the dynamic response data of modal analyses in aircraft's structures can be identified through numerical methodologies as in [17].

Flow analysis by means of CFD is an alternative to carrying out expensive experimental tests performed, for example, with fully developed flows with high Reynolds numbers [18]. In this regard, a numerical model, based on the methods of the panels and images is proposed to analyze the influence of the dynamic ground effect on the aerodynamic characteristics of a rectangular wing [19]. On the other hand, the finite element method (FEM) allows, for example, designing a landing gear during the conceptual stage to analyze the impact loads during take-off and landing of an unmanned aircraft [20]. However, throughout the process of the conceptual design stage, problems may arise in the adaptation of mesh generation tools with other design programs. In this regard, a description list of programs used in the conceptual phase of aircraft design is displayed and highlights the increasing time designers spend on repetitive tasks such as mesh generation and refinement or iterative calculation for post-process analysis. To this end, a modeling methodology consisting of the parametrization of geometric variables of the external surfaces of an aircraft is proposed in order to increase the efficiency of the design process. In this way, the next new step for design and optimization consists of the fully automated framework of aircraft components [21]. A fully automated framework dedicated to the high-fidelity multidisciplinary design optimization of the passenger aircraft wing is developed, integrating a set of popular commercial software using their scripting capabilities [22].

Following this trend, this work focuses on the development of a methodology for the design of control surfaces in radio-controlled and unmanned aircraft that allows the improvement of efficiency in the design phase and provides the designer with more time for analyses in other design areas. The control surfaces considered are the elevator, the ailerons and the rudder. For the modeling, the proposed methodology considers the use of the open-source CFD program XFLR5 [23]. The work is structured as follows; Section 2 
describes the guidelines for the development of the design methodology for each of the control surfaces involved. Section 3 details the numerical and analytical approach to the methodology applied to control surfaces in radio-controlled experimental airplanes. Section 4 presents the results of applying the methodology to the latest aircraft design: the aileron's design sensitivity analysis and the optimization of the control surfaces weight in relation to the aircraft's takeoff weight.

\section{Methodology}

The first step to develop the design methodology is to classify the aircraft according to its Class, Phases of Flight, and Levels of Acceptability. This classification is made following FAA (Federal Aviation Administration) Part 23 airworthiness regulations for GA utility aircraft [24] and Mil-F8785C military standards for aircraft design used by the USAF (The United States Air Force) [25]. This allows us to set a working envelope for design as stated by aeronautical regulators regarding control requirements. The prototype is considered as a utility aircraft with a maximum takeoff weight (MTW) less to 6000 $\mathrm{Kg}$. After the prototype is tossed, it must climb up to a determined height, then must complete turns, descent and land. During this mission, it is essential that the aircraft responds effectively to the control orders. Therefore, the prototype is defined as a "Class I" aircraft that must accomplish "Phase C" flight operations and from which is expected a "Level 1" of Acceptability.

\subsection{Considered design variables}

Design variables are categorized according to each control characteristics and requirements. The variables are classified in: environmental variables, geometrical variables, aerodynamic variables, and inertial variables. Table 1 summarizes some relevant environmental variables.

Table 1 Environmental variables applicable to the flight mission, FAA Handbook [26]

\begin{tabular}{|c|c|c|}
\hline Variables & Symbol & Comments \\
\hline Ambient Temperature & $T$ & $\begin{array}{l}\text { According to ISA } \\
\text { conditions }\end{array}$ \\
\hline Barometric Pressure & $P$ & $\begin{array}{l}\text { According to ISA } \\
\text { conditions }\end{array}$ \\
\hline Average Humidity & $H$ & $\begin{array}{l}\text { According to field } \\
\text { conditions }\end{array}$ \\
\hline Air Density & $\rho$ & $\begin{array}{l}\text { According to ISA } \\
\text { conditions }\end{array}$ \\
\hline Crosswind Speed & $V_{W}$ & $\begin{array}{l}\text { According to field } \\
\text { conditions }\end{array}$ \\
\hline Wind Speed & $W$ & $\begin{array}{l}\text { According to field } \\
\text { conditions }\end{array}$ \\
\hline
\end{tabular}

Geometrical Variables depend on lifting surface size lwing and empennage). These variables are interrelated with other aircraft's components, and designers must consider its relative position to the center of gravity $(C G)$ of the airplane. Some geometrical variables are the mean aerodynamic chord (MAC), the wingspan $(b)$ and the aspect ratio $(A R)$. The geometrical variables shown in Table 2 are restrained to the values specified.

Table 2 Recommended design values for control surface design, Sadraey [27]

\begin{tabular}{cccc}
\hline Control Surface & Aileron & Rudder & Elevator \\
\hline Planform surface ratio & $\frac{S_{A}}{S}=0.03-0.12$ & $\frac{S_{R}}{S_{V}}=0.15-0.35$ & $\frac{S_{A}}{S_{h}}=0.15-0.40$ \\
Chord ratio & $\frac{C_{A}}{C}=0.15-0.30$ & $\frac{C_{R}}{C_{V}}=0.15-0.40$ & $\frac{C_{E}}{C_{h}}=0.20-0.40$ \\
Span ratio & $\frac{b_{A}}{b}=0.20-0.40$ & $\frac{b_{R}}{b_{V}}=0.70-1$ & $\frac{b_{E}}{b_{h}}=0.03-0.12$ \\
Maximun deflection (-) & $25^{\circ}($ Up) & $30^{\circ}$ (Right Hand) & $25^{\circ}$ (Up) \\
Maximun deflection (+) & $20^{\circ}$ (Down) & $30^{\circ}$ (Left Hand) & $20^{\circ}$ (Down) \\
\hline
\end{tabular}

The methodology evaluates geometrical relations from the minimum recommended value. If the minimum value does not satisfy the design requirements for that specific design stage, designers evaluate the next higher value until the requirement is met. Inertial variables are related to the airplane's moments of inertia with respect to the CG. These variables depend on the punctual masses of each structural element, electronic components, and the payload of the airplane, see Table 3.

Table 3 Inertial Variables applicable to the methodology

\begin{tabular}{cccccc}
\hline Inertial Variables & Symbol & Unit & Aileron & Elevator & Rudder \\
\hline Aircraft's mass & $m$ & $\mathrm{~kg}$ & & $X$ \\
Inertia about the lateral axis & $I_{Y Y}$ & $\mathrm{~kg} \cdot \mathrm{m}^{2}$ & & $X$ & \\
Inertia about the longitudinal axis & $I_{X X}$ & $\mathrm{~kg} \cdot \mathrm{m}^{2}$ & $X$ & & \\
\hline
\end{tabular}

\subsection{General considerations for control surface design}

Once the variables are presented, some general design considerations must be established. The CG position is fixed during the flight mission because it is a UAV and does not burn fuel. The maximum control surface deflection must be less than the control deflection that causes the stall of the respective lifting surface [28].

\section{Elevator design}

The elevator is the longitudinal control surface about the lateral axis of the airplane. When the elevator is deflected upwards, the tail's lift coefficient $\left(C_{L_{h}}\right)$ decreases, producing a nose-up pitching moment and causing the aircraft to climb. Operation is reverted when the elevator is deflected downwards. This surface helps to maintain longitudinal stability and is generally mounted in the horizontal stabilizer covering a portion of its chord. For elevator design must be established that: al deflections 
$\left(\delta_{E}\right)$ will be positive $(+)$ downwards, b) a positive deflection $(+)$ increases the horizontal stabilizer's lift, generating an upward movement of the tail and a (-) pitching moment that causes the aircraft to descent. Table 4 indicates the parameters to obtain using the methodology:

Table 4 Parameters to obtain as a result of the elevator design

\begin{tabular}{cc}
\hline Parameters of the elevator & Expression \\
\hline Elevator - Horizontal Stabilizer chord ratio & $\frac{C_{E}}{C_{h}}$ \\
Elevator - Horizontal Stabilizer span ratio & $\frac{b_{E}}{b_{h}}$ \\
Maximum deflection (-) at takeoff & $\delta_{\max T O}$ \\
Maximum deflection (+) in cruise flight & $\delta_{\max C r}$ \\
\hline
\end{tabular}

\section{Aileron design}

Ailerons provide lateral control about the plane's longitudinal axis. For the ailerons, it must be taken into count that: a) every deflection $\left(\delta_{A}\right)$ will be positive $(+)$ if produces a clockwise roll and b) every $(+)$ deflection decreases the lift in the right wing and increases the lift in the left wing. This situation induces a clockwise roll and a subsequent turn to the right. The parameters to determine in the aileron methodology are shown in Table 5.

Table 5 Parameters to obtain as a result of the ailerons design

\begin{tabular}{cc}
\hline \multicolumn{1}{c}{ Parameters of the ailerons } & Expression \\
\hline $\begin{array}{r}\text { Maximum deflection }\left(\delta_{A}\right)(+) \text { and (-) } \\
\text { of the ailerons }\end{array}$ & $\delta_{A}$ \\
\hline $\begin{array}{l}\text { Inner tip coordinate of the aileron along } \\
\text { the wingspan, taken from the wing root }\end{array}$ & $b_{A i}$ \\
\hline $\begin{array}{l}\text { Outer tip coordinate of the aileron along } \\
\text { the wingspan, taken from the wing root }\end{array}$ & $b_{A o}$ \\
\hline
\end{tabular}

\section{Rudder design}

The Rudder provides directional control with respect to the vertical axis of the plane. The guidelines for the development of the methodology consider that: a) rudder deflection $\left(\delta_{R}\right)$ will be positive $(+)$ to the left and b) positive deflection of the rudder produces a lateral force on the vertical stabilizer in the right direction, generating a negative yaw moment that turns the aircraft nose towards the left. The parameters to determine in the methodology are appreciated in Table 6. Landing and takeoff in crosswind conditions are the most critical condition for the rudder operation.
Table 6 Parameters to obtain as a result of the rudder design

\begin{tabular}{cc}
\hline Parameters of the rudder & Expression \\
\hline Rudder chord & $C_{R}$ \\
Maximum deflection of the rudder & $\delta_{R}$ \\
\hline
\end{tabular}

\section{Methodology development}

The control surface design process is presented by posing the design methodology for ailerons, elevator, and rudder.

\subsection{Elevator design methodology}

The goal is to calculate the elevator's efficiency $\left(\tau_{E}\right)$ in order to determine the chord relation between the elevator and the horizontal stabilizer $\left(\frac{C_{E}}{C_{h}}\right)$ and, ultimately, the elevator chord $\left(C_{E}\right)$. Figure 1 shows the chord ratio as a function of the elevator efficiency.

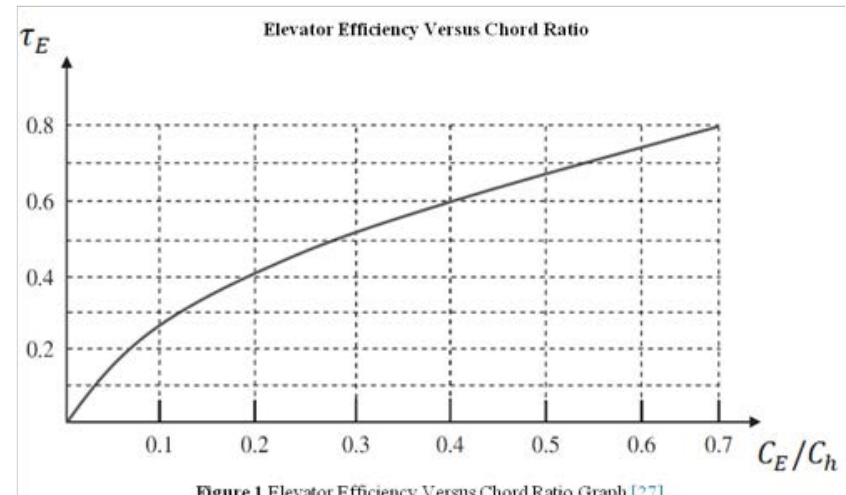

Figure 1 Elevator efficiency versus chord ratio graph [27]

If $\tau_{E}>0.7$ then $\frac{C_{E}}{C_{h}}>0.5$. Otherwise, if $\frac{C_{E}}{C_{h}}>0.5$, then a separation of the boundary layer of the airflow on the top of the airfoil is likely to occur, and stall could be induced [29]. Thus, it is recommended that $\frac{C_{E}}{C_{h}} \in[0.2-0.5]$.

\section{Phase num. 1 Identification of longitudinal control requirements and determination of the elevator chord $C_{E}$ :}

The elevator efficiency is calculated from Equation 1 and $\left(\alpha_{h}\right)$ is the angle of attack of the horizontal stabilizer, see Equation 2.

$$
\begin{gathered}
\tau_{e}=\frac{C_{L_{h}}-\left(C_{L_{a h}} \alpha_{h}\right)}{C_{L_{\alpha h}} \delta_{E t o}} \\
\alpha_{h}=\alpha+i_{h}-\varepsilon
\end{gathered}
$$

where $\left(C_{L_{h}}\right)$ is the horizontal stabilizer lift coefficient, see Equation 6, $\left(C_{L_{\alpha h}}\right)$ is the slope of the coefficient of lift of the horizontal stabilizer about the angle of attack 
(AOA) of the aircraft obtained from an analysis performed in the XFLR5 program. $\left(\delta_{E t o}\right)$ is the elevator's maximum negative deflection (upwards) selected from the data in Table 2. From Equation 2, $\left(\alpha_{h}\right)$ is the angle of attack of the horizontal stabilizer, $\alpha$ is the AOA of the aircraft during rotation and $\left(i_{h}\right)$ is the angle of incidence of the horizontal stabilizer. While in Equation 3, $(\epsilon)$ is the downwash angle, represented by the flow lines that abandon the wing by its trailing edge and that are projected over the aircraft's tail, $\left(\epsilon_{0}\right)$ is the angle of downwash when the wing has a AOA of $0^{\circ}$, see Equation 4.

$$
\begin{gathered}
\varepsilon=\varepsilon_{0}+\left(\frac{d \varepsilon}{d \alpha}\right) \alpha \\
\varepsilon_{0}=\frac{2 C_{L_{0}}}{\pi A R} \\
\frac{d \varepsilon}{d \alpha}=\frac{2 C_{L_{\alpha}}}{\pi A R}
\end{gathered}
$$

$\left(C_{L_{0}}\right)$ is the coefficient of lift of the aircraft when the AOA $=0^{\circ}$ and from Equation $5\left(\frac{d \epsilon}{d \alpha}\right)$ is the variation of the curve's slope between $(\epsilon)$ and the AOA, $\left(C_{L_{\alpha}}\right)$ is the curve's slope between the lift coefficient and the AOA which is obtained from the analysis performed in the XFLR5 program and AR is the wing's aspect ratio which value comes from previous stages of the aircraft design. The coefficient of lift of the horizontal stabilizer horizontal $\left(C_{L_{h}}\right)$ is calculated with Equation 6, where $\left(L_{h}\right)$ is the horizontal tail's lift, which is obtained from diagramming the forces present in an aircraft during takeoff, determined by Equation 7 and $\left(S_{h}\right)$ is the planform surface of the horizontal stabilizer.

$$
C_{L_{h}}=\frac{2 L_{h}}{\rho V_{\infty}^{2} S_{h}}
$$

$$
L_{h}=\frac{\left[L_{w f}\left(X_{m g}-X_{a c_{w f}}\right)+M_{a c_{w f}}+m \cdot a\left(Z_{c g}-Z_{m g}\right)-W\left(X_{m g}-X_{c g}\right)+D\left(Z_{D}-Z_{m g}\right)-T\left(Z_{T}-Z_{m g}\right)-I_{y y m g} \ddot{\theta}\right]}{X_{a c_{h}}-X_{m g}}
$$

During takeoff, the control mission of the elevator is critical because it has to overcome the inertia and elevate the aircraft off the ground. Figure 2 represents the forces present in an aircraft at the moment of takeoff and Table 7 shows a summary of them.

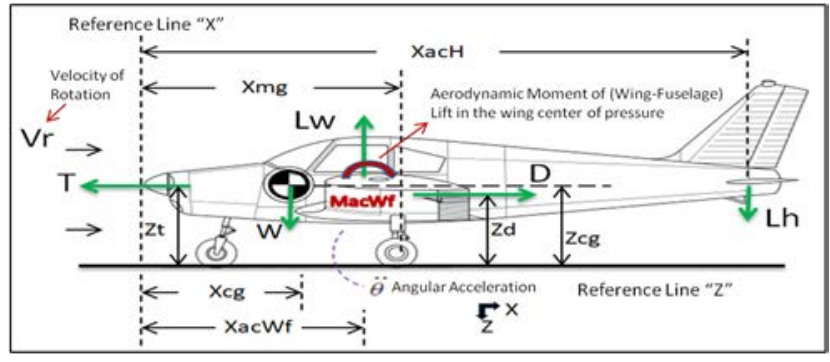

Figure 2 Representation of the forces present in an aircraft at the moment of takeoff
From Equation 7, $(\ddot{\theta})$ is the recommended angular acceleration for the aircraft during takeoff, $a$ is the linear acceleration about the longitudinal axis at the moment of tossing the aircraft and $\left(L_{w f}\right)$ is the combined lift force of the wing and fuselage. The fuselage contribution in the generation of lift is approximately $10 \%$ of the wing lift [30]. In the case of the micro category aircraft's, the fuselage has minimum influence regarding the generation of lift. Therefore, it is assumed that $L_{w f} \approx L_{w}$, see Equation 8 and $\left(X_{a c_{w f}}\right)$ is the distance to the wing-fuselage aerodynamic center which is located at $\pm 5 \%$ of the MAC, mean aerodynamic chord, and the aerodynamic center of the wing at $\pm 25 \%$ of the MAC [31]. As $L_{w f} \approx L_{w}$ then $\left(X_{a c_{w f}}\right)$ is located at $25 \%$ of the MAC. In Equation 8, $\left(V_{R}\right)$ is the aerodynamic variable that indicates the aircraft's linear speed during takeoff rotation. In order to increase the safety, the margin is considered equal to the stall speed $\left(V_{S}\right)$, and $\left(C_{L_{T O}}\right)$ is the coefficient of lift of the aircraft at takeoff.

$$
\begin{gathered}
L_{w f}=\frac{1}{2} \rho V_{R}^{2} C_{L_{T O}} S \\
M_{a c_{w f}}=\frac{1}{2} \rho V_{R}^{2} C_{M_{a c_{w f}}} \frac{C}{}
\end{gathered}
$$

From Equation 9, $\left(M_{a c_{w f}}\right)$ is the wing-fuselage moment in its aerodynamic center, where $(\underline{C})$ is the MAC. Under the consideration $L_{w f} \approx L_{w}$, then $M_{a c_{w f}}=M_{a c_{w}}$, and in the same manner the coefficient of moments $C_{M_{a c_{w f}}}=C_{m}$. As long the Micro class prototype does not have landing gear, its $\left(X_{m g}\right)$ position will be treated as the longitudinal position by which the aircraft is held when being tossed.

Vertical references of the aircraft are measured with respect to the $\left(Z_{m g}\right)$ coordinate of the launching point. $\left(C_{D T O}\right)$ is the coefficient of drag during takeoff, obtained by means of XFLR5. The action lines of Thrust $(T)$ and Drag $(D)$ forces also produce changes in pitch because they are not aligned with the longitudinal axis of the airplane. Once $\left(L_{h}\right)$ is obtained, it is substituted in Equation 6 (checked in phase 2) and, in turn in, Equation $\tau_{E}$ and $C_{E}$ are calculated. If $\frac{C_{E}}{C_{h} \in[0.2-0.5]}$ the phase is culminated.

\section{Phase num. 2 comparison of results $\left(C_{L_{h}}\right)$ with XFLR5}

It is checked that the horizontal stabilizer lift coefficient value $\left(C_{L_{h}}\right)$ is approximate to the one calculated using numeric methods, to the one obtained by the CFD modelling. In this case, with XFLR5 program under the same flow conditions and the same angle of attack. Given some previous experiences of the design team with aero models, a difference of less to $25 \%$ between both results is considered acceptable. 
Table 7 Forces present in an aircraft at the moment of takeoff

\begin{tabular}{|c|c|c|c|c|c|}
\hline Forces & Name of the variable & Arm $X$ axis & Name of the variable & Arm $Z$ axis & Name of the variable \\
\hline$D$ & $\begin{array}{l}\text { Drag determined from } \\
\qquad C_{D T O}\end{array}$ & $X_{a c} h$ & $\begin{array}{l}\text { Distance from the reference line to the } \\
\text { aerodynamic center of the horizontal stabilizer }\end{array}$ & $Z_{c g}$ & $\begin{array}{l}\text { Distance from the launching } \\
\text { point of the aircraft to its CG }\end{array}$ \\
\hline$L_{h}$ & $\begin{array}{l}\text { Lift of the } \\
\text { horizontal stabilizer }\end{array}$ & $X_{a c_{w f}}$ & $\begin{array}{l}\text { Distance from the reference line to the } \\
\text { aerodynamic center of the wing-fuselage }\end{array}$ & $Z_{D}$ & $\begin{array}{l}\text { Distance from the launching } \\
\text { point of the aircraft to the action line of } D\end{array}$ \\
\hline$L_{w}$ & $\begin{array}{l}\text { Lift of the wing determined } \\
\text { from } C_{L T O}\end{array}$ & $X_{c g}$ & $\begin{array}{l}\text { Distance from the reference } \\
\text { line to the aircraft's } C G\end{array}$ & $Z_{T}$ & $\begin{array}{l}\text { Distance from the launching point } \\
\text { of the aircraft to the action line of } \mathrm{T}\end{array}$ \\
\hline$T$ & Engine thrust & $X_{m g}$ & $\begin{array}{l}\text { Distance from the reference } \\
\text { line to the aircraft's landing gear }\end{array}$ & $Z_{m g}$ & $\begin{array}{l}\text { Vertical coordinate of the } \\
\text { aircraft's launching point }\end{array}$ \\
\hline
\end{tabular}

\section{Phase num. 3 calculus of the maximum deflection at cruise $\left(\delta_{\max _{c r}}\right)$}

This phase consists of evaluating the elevator control function of assuring longitudinal stability in cruise flight. The aerodynamic forces present in an aircraft during takeoff are considerably different from those found in cruise flights. During the flight, the maximum deflection $\left(\delta_{\max _{C r}}\right)$ required for keeping the aircraft's longitudinal control is less than during takeoff. In Figure 3, the forces present in an aircraft during cruise flight are shown.

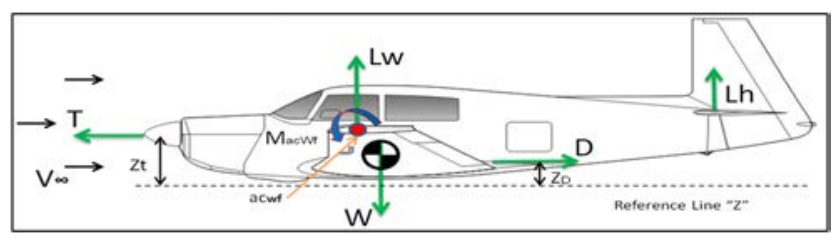

Figure 3 Representation of the forces present in an aircraft in cruise flight

Designers must verify that the maximum positive deflection during cruise flight $\left(\delta_{E_{C r}}\right)$ is less than the maximum negative deflection at takeoff $\left(\delta_{E_{T O}}\right)$, Equation 10. For this verification, three longitudinal control derivatives are calculated by Equation 11 (Pitch moment control derivate, $C_{M_{\delta_{E}}}$ l, Equation 12 laircraft lift control derivative, $C_{L_{\delta_{E}}}$ ), Equation 13, (Horizontal stabilizer lift control derivative, $C_{L_{h_{\delta_{E}}}}$ l, respectively.

$$
\begin{gathered}
\left(\delta_{E_{c r}}\right)<\left(\delta_{E_{T O}}\right) \\
C_{M_{\delta_{E}}}=-\frac{d C_{M}}{d \delta_{E}}=-C_{L_{\alpha h}} \eta_{h} V_{h} \frac{b_{E}}{b_{h}} \tau_{E} \\
C_{L_{\delta_{E}}}=\frac{d C_{L}}{d \delta_{E}}=C_{L_{\alpha h}} \eta_{h} V_{h} \frac{S_{h}}{S} \frac{b_{E}}{b_{h}} \tau_{E} \\
C_{L_{h_{\delta_{E}}}}=\frac{d C_{L_{h}}}{d \delta_{E}}=C_{L_{\alpha h}} \tau_{E}
\end{gathered}
$$

$\left(\eta_{h}\right)$ is the tail efficiency Dynamic Pressure ratio in the zone of the horizontal stabilizer [32]. Its reference value ranges between 0.85 and $0.95 .\left(V_{h}\right)$ is the volume coefficient of the horizontal stabilizer, a value that must have been calculated in previous design stages. $\left(b_{E}\right)$ and $\left(b_{h}\right)$ are the elevator and horizontal stabilizer spans, respectively.
Thus, maximum (+) deflection in cruise flight is, Equation 14.

$$
\delta_{E_{c r}}=\frac{\left(\frac{T Z_{T}}{q S C}+C_{m_{0}}\right) C_{L_{\alpha}}+\left(C_{L_{1}}-C_{L_{0}}\right) C_{m_{\alpha}}}{C_{L_{\alpha}} C_{M_{\delta_{E}}}-C_{m_{\alpha}} C_{L_{\delta_{E}}}}
$$

$\left(C_{m_{0}}\right)$ is the aircraft's pitching moment coefficient obtained by XFLR5 when AOA $=0^{\circ},\left(C_{m_{\alpha}}\right)$ is aircraft's pitching moment curve slope as a function of the change in the AOA, which is determined by analysis in XFLR5 and $(q)$ is the dynamic pressure in the elevator. From Equation 15, $\left(C_{L_{1}}\right)$ is the coefficient of lift in cruise flight, and $W$ is the aircraft's MTW.

$$
C_{L_{1}}=\frac{W}{q S}
$$

Finally, if the Equation 10 criterion is accomplished, then the phase culminates. If it is not accomplished, designers must return to phase num. 1. Ultimately, from $\left(\frac{C_{E}}{C_{h}}\right)$ a $\left(C_{E}\right)$ value is calculated.

\section{Phase num. 4 stall at takeoff avoidance}

It must be verified that the elevator deflection at takeoff does not induce a stall over the horizontal stabilizer during takeoff. According to the recommendation in Table 2, if the downward or upward elevator's deflection does not exceed $25^{\circ}$, then stall should not occur. Thus, designers recommend a maximum upwards and downwards deflection of $25^{\circ}$ in order to avoid a stall.

\subsection{Aileron design methodology}

In this section, the parameters related to the aileron design are calculated; some of them are the steady- state roll rate $\left(P_{S S}\right)$, the moment of roll $\left(L_{A}\right)$, the aerodynamic coefficient of the aileron during roll $\left(C_{l a}\right)$, and its control derivative $\left(C_{l_{\delta_{A}}}\right)$.

\section{Phase num. 1 identification of lateral control requirements and determination of preliminary geometrical relations}

Some preliminary geometrical relations are to be determined, specifically the inner $\left(b_{A_{i}}\right)$ and outer $\left(b_{A_{o}}\right)$ 
aileron tips coordinate along the aircraft's lateral axis, see Table 5. By recommendations of the military standards, the outer tip of the aileron is located between an $85 \%$ and $90 \%$ of the half-wing span $(b / 2)$ and that the span ratio $\left(\frac{b_{A_{i}}}{b}\right)$ is in the range of 0.6-0.8 [27]. A preliminary aileron-to-wing chord $\left(\frac{C_{A}}{C}\right)$ was also selected, as shown in Table 2. From this relation, the aileron's efficiency $\left(\tau_{A}\right)$ was determined to be used in later stages of the design. Based on the geometry relations, the designer calculates the Steady State Roll Rate (PSS). This condition occurs when the Roll moment is balanced with the Restoring moment caused by the airplane's lateral stability. If the ailerons do not return to their neutral position, the airplane will continue to roll until the wings reach an angle where no further lift can be generated. $(P S S)$ can be calculated by Equation 16.

$$
P_{S S}=\sqrt{\frac{2 L_{A}}{\rho\left(S+S_{h}+S_{v}\right) C_{D_{R}} Y_{d}^{3}}}
$$

$\left(S_{v}\right)$ is the vertical stabilizer planform surface, $\left(C_{D_{R}}\right)$ is the coefficient of drag during roll determined from XFLR5, $\left(Y_{d}\right)$ is the coordinate of mean drag of the three lifting surfaces (wing, horizontal and vertical stabilizers) located at $40 \%$ of the aircraft's half-wing span measured from the wing root. $\left(L_{A}\right)$ is the moment of roll due to the maximum aileron deflection, given by Equation 17.

$$
\begin{gathered}
L_{A}=q S C_{l a} b \\
C_{l a}=C_{l_{\delta_{A}}} \delta_{A \max }
\end{gathered}
$$

where $(b)$ is the aircraft's wingspan and $\left(C_{l a}\right)$ is the aerodynamic coefficient of the aileron during roll, Equation 18. From that Equation, $\left(\delta_{A \max }\right)$ is the maximum aileron deflection in radians whose selection is recommended in Table 2 and $\left(C_{l_{\delta_{A}}}\right)$ is the lateral control derivative of the aileron aerodynamic coefficient during roll, obtained from Equation 19. When integrating within the inner $\left(b_{A_{i}}\right)$ and outer $\left(b_{A_{o}}\right)$ coordinates of the aileron and considering a tapered wing $(\lambda)$, Equation 20 is obtained.

$$
\begin{gathered}
C_{l_{\delta_{A}}}=\frac{2 C_{L_{\alpha}} \tau_{A}}{S b} \int_{b_{A_{i}}}^{b_{A_{0}}} C y d x \\
C_{l_{\delta_{A}}}=\frac{2 C_{L_{\alpha}} \tau_{A} C}{S b}\left[\frac{y^{2}}{2}+\frac{2}{3}\left(\frac{\lambda-1}{b}\right) y^{3}\right]
\end{gathered}
$$

$\left(C_{L_{\alpha}}\right)$ is the ratio of change of the aircraft's lift coefficient about the angle of attack and it is considered constant along the wingspan. Factor " 2 " is inserted in the equation because there are two ailerons.

\section{Phase num. 2 bank angle calculation $\left(\phi_{1}\right)$}

The bank angle $(\phi)$ is that angle formed between the horizon and the aircraft's wings as observed in Figure 4. For the prototype's classification, the military standards indicate that the aircraft must reach a determined bank angle in a specific time. This angle and time are denoted as $\left(\phi_{r e q}\right)$ and $\left(t_{r e q}\right)$ and for the aircraft's classification they have the values of $30^{\circ}$ and 1.3 s respectively, according to the standard Mil-Std 8785-C [25]. With the $\left(P_{S S}\right)$ is calculated the bank angle $\left(\phi_{1}\right)$ following the selected conditions from Equation 21.

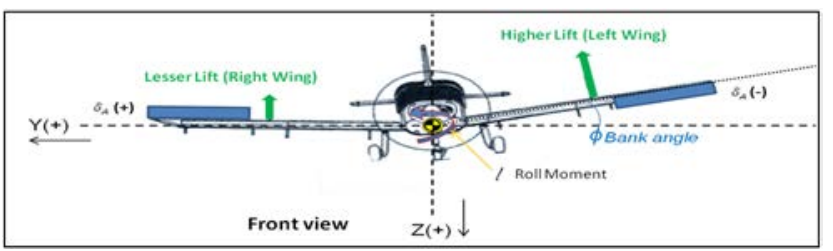

Figure 4 Representation of the forces present in an aircraft at the moment of a roll

$$
\begin{gathered}
\phi_{1}=\frac{I_{x x}}{\rho\left(S+S_{h}+S_{v}\right) C_{D_{R}} Y_{d}^{3}} \ln \left(P_{S S}^{2}\right) \\
t_{(\phi r e q)}=\sqrt{\frac{2 \phi_{r e q}}{\dot{P}}} \\
\dot{P}=\frac{P_{S S}^{2}}{2 \phi_{1}}
\end{gathered}
$$

If $\phi_{1}>\phi_{\text {req }}$ then calculate $t_{\left(\phi_{\text {req }}\right)}$ by Equation 22. $t_{\left(\phi_{r e q}\right)}$ is the time that the aircraft needs to reach the required bank angle $\left(\phi_{\text {req }}\right)$. For that, the rate of roll $(\dot{P})$ is determined in Equation 23. If $\phi_{1}<\phi_{r e q}$, then calculate $\left(t_{2}\right)$, which is the time that the aircraft needs in order to reach the required bank angle $\left(\phi_{\text {req }}\right)$. This time is the sum of the time that the aircraft takes to reach the steady-state roll rate $\left(t_{s s}\right)$ and the time difference $\left(\Delta t_{R}\right)$ for reaching the required bank angle; this is calculated as indicated in Equations 24, 25 and 26 .

$$
\begin{gathered}
t_{s s}=\sqrt{\frac{2 \phi_{1}}{\dot{P}}} \\
t_{2}=t_{s s}+\Delta t_{R} \\
\Delta t_{R}=\frac{\phi_{r e q}-\phi_{1}}{P_{S S}}
\end{gathered}
$$

A maximum difference between $t_{\left(\phi_{\text {req }}\right)}$ and $\left(t_{2}\right)$ must not exceed $10 \%$. If this condition is fulfilled, this phase is finished. On the contrary, return to phase num. 1, selecting the coordinates of the aileron tips. If the aircraft is under the requirement for its roll performance, then the initial span relations were correctly selected, and it is now a process of optimization whereby the number approaches that of the requirement. 


\section{Phase num.3 stall in operation avoidance}

According to the recommendation in Table 2, if the downward or upward aileron's deflection does not exceed $25^{\circ}$, then stall should not occur. Generally, the airplane is designed for a stall to occur from the root of the wing in direction to the tip, allowing lateral control for the longest possible time. Nevertheless, aerodynamic studies on stall conditions are outside this research scope.

\subsection{Rudder design methodology}

The rudder should be capable of keeping aircraft's directional control in every; still, a specific control mission is determined, for example, aerobatic maneuvers or adverse weather operations. For Micro class aeromodels, it has been determined that the critical control mission of the rudder is to keep directional control in flight with a crosswind [33].

\section{Phase num. 1 identification of directional control requirements and selection of critical flight control mission}

According to the Federal Aviation Regulations (FAR) in their section $N^{\circ} 23$, utility aircraft must keep directional control while in a crosswind blowing perpendicular to their flight trajectory [24]. In a similar sense, the military standard establishes that the maximum wind component which is applicable for design must be 20 knots for these types of model's classification [25]. However, considering the small size of the model aircraft, it is convenient to design for a maximum wind component between 8 and 10 knots. Furthermore, it is worth mentioning that this crosswind operation is more critical during takeoff and landing phases, when the flight speed approaches the stall speed of the aircraft $\left(V_{S}\right)$. The relative wind $\left(V_{T}\right)$ corresponds to the combined components of the wind coming from in front of the aircraft and the crosswind, as observed in Equation 27.

$$
V_{T}=\sqrt{U_{1}^{2}+V_{W}^{2}}
$$

Wind loads are applied in a point denominated aerodynamic center $\left(X_{A C}\right)$ this point is located in the airplane's profile over the side surface exposed to the wind $\left(S_{S}\right)$. For calculating that area's centroid, the model profile is subdivided into areas of recognizable geometry, and the " $x$ " coordinate of the centroid of the surface is calculated as in Equation 28.

$$
X_{A C}=\frac{\sum_{i=1}^{n} A_{i} X_{i}}{\sum_{n=1}^{n} A_{i}}
$$

In this equation, $\left(A_{i}\right)$ corresponds to the area of each figure comprising the total surface, $\left(X_{i}\right)$ is the coordinate of each figure's centroid about the aircraft's longitudinal axis. The aerodynamic center is separated from the model CG by a distance called $\left(d_{c}\right)$. According to the directional stability analysis in XFLR5 program, it is favorable to flight operations that the aerodynamic center $\left(X_{A C}\right)$ is located behind the aircraft's CG.

\section{Phase num. 2 rudder deflection $\left(\delta_{R}\right)$ and crab angle $(\sigma)$ calculation}

To control the airplane in crosswinds, the pilot must correct the drift by the action of the rudder, this maneuver is called crabbing and allows the aircraft to stay on course without sliding in the wind. The Crab angle $(\sigma)$ is the angle formed between the direction of the relative wind and the longitudinal axis of the aircraft, Figure 5.

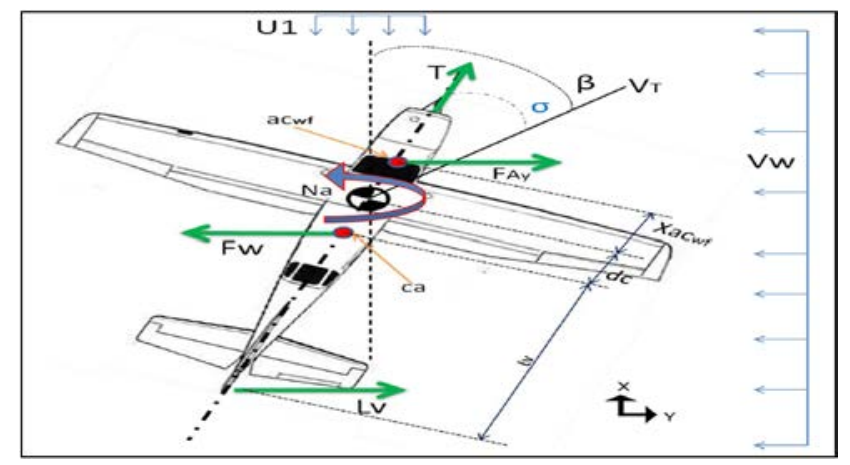

Figure 5 Representation of the forces present in an aircraft during crosswind operations

To calculate rudder deflection and crab angle, designers need to: select a rudder-vertical stabilizer chord $\left(\frac{C_{R}}{C_{V}}\right)$ according to Table 2. Utilizing this ratio, the rudder effectiveness $\left(\tau_{R}\right)$ is obtained from Figure 1, performing a mechanical analysis of the forces present during crosswind operations as seen in Figure 5. This mechanical analysis results in a system of nonlinear equations which is constituted by aerodynamic, environmental and geometric variables. The system of equations must be solved to obtain the rudder deflection $\left(\delta_{R}\right)$ and the crab angle $(\sigma)$, Equations 29 and 30.

$\frac{1}{2} \rho V_{T}^{2} S b\left[C_{n_{0}}+C_{n_{\beta}}(\beta-\sigma)+C_{n_{\delta_{R}}} \delta_{R}\right]+F_{W} \cos d_{c} \cos \sigma=0$

$\frac{1}{2} \rho V_{W}^{2} S_{S} C_{D_{Y}}-\frac{1}{2} \rho V_{T}^{2} S\left[C_{y_{0}}+C_{y_{\beta}}(\beta-\sigma)+C_{y_{\delta_{R}}} \delta_{R}\right]=0$

where $\left(\delta_{R}\right)$ is the maximum rudder deflection recommended by Table 2, $\left(F_{W}\right)$ is referred to the wind force calculated as a function of the side area $\left(S_{S}\right)$ and of the crosswind component $\left(V_{w}\right)$, Equation 31. In the same equation, $\left(C_{D_{Y}}\right)$ is the coefficient of side drag that 
has a value between 0.5 and 0.8 [27]. $\beta$ is the sideslip, obtained from Equation 32.

$$
\begin{gathered}
F_{W}=\frac{1}{2} \rho V_{W}^{2} S_{S} C_{D_{Y}} \\
\beta=\left(\frac{V_{W}}{U_{1}}\right) \\
C_{y_{\beta}}=-K_{f_{2}} C_{L_{\alpha_{v}}}\left(1-\frac{d \sigma}{d \beta}\right) \eta_{v} \frac{S_{v}}{S} \\
C_{n_{\beta}}=-K_{f_{1}} C_{L_{\alpha_{v}}}\left(1-\frac{d \sigma}{d \beta}\right) \eta_{v} \frac{l_{v} S_{v}}{b S}
\end{gathered}
$$

From Equation 33, $\left(C_{y_{\beta}}\right)$ is the stability derivative that measures the aircraft's change of directional position about the sideslip angle. This derivative's calculation considers the contribution of the fuselage, wing, and vertical tail, in which the vertical tail has the most significant contribution [34]. In Equation 34, $\left(C_{n_{\beta}}\right)$ represents the stability derivative that measures the change in the yaw moment about the sideslip angle [27], $\left(C_{L_{\alpha_{v}}}\right)$ corresponds to the slope of the vertical stabilizer coefficient of lift about the AOA. This aerodynamic variable comes from a numeric analysis in XFLR5 program. $\left(\eta_{v}\right)$ is the dynamic pressures ratio in the zone of the vertical stabilizer [32]; this has a recommended value between $85 \%$ and $95 \%$. $\left(l_{v}\right)$ measures the vertical stabilizer arm, $\left(S_{v}\right)$ is the vertical stabilizer planform surface, $\left(K_{f_{1}}\right)$ is a correction factor for the fuselage contribution to the control derivative $\left(C_{n_{\beta}}\right)$ and is between $\left(0.65<K_{f_{1}}<\right.$ 0.85) [27]. $\left(K_{f_{2}}\right)$ is a correction factor the fuselage contribution to the control derivative $\left(C_{y_{\beta}}\right)$ and is between $\left(0.75<K_{f_{2}}<1\right)$ [35]. Because the model's fuselage aerodynamic contribution is considerably small $\left(K_{f_{1}}\right)$ and $\left(K_{f_{2}}\right)$ are considered to be less than the recommended values. To calculate directional control derivatives, $\left(C_{y_{\delta_{R}}}\right)$ and $\left(C_{n_{\delta_{R}}}\right)$, are developed in Equations 35 and 36 .

$$
\begin{gathered}
C_{y_{\delta_{R}}}=C_{L_{\alpha_{v}}} \eta_{v} \tau_{R} \frac{b_{R}}{b_{V}} \frac{S_{R}}{S_{V}} \\
C_{n_{\delta_{R}}}=-C_{L_{\alpha_{v}}} V_{V} \eta_{v} \tau_{R} \frac{b_{R}}{b_{V}}
\end{gathered}
$$

$\left(V_{V}\right)$ and $\left(b_{V}\right)$ are the coefficient of volume of the vertical stabilizer and its span determined in previous aircraft design stages, respectively. Once the elements for the equations system are obtained, the system is solved to obtain the crab angle $(\sigma)$ and the rudder's deflection $\left(\delta_{R}\right)$.

\section{Phase num. 3 stall in operation avoidance}

If $\left(\delta_{R}\right)$ obtained from the system of equations is less than the maximum required to avoid a stall in the vertical stabilizer, the $\left(\frac{C_{R}}{C_{V}}\right)$ relation must be modified, and the designers must return to phase 2 . On the contrary, the design is finished.

\subsection{Selection of servomotors}

To determine the required torque to actuate the control surfaces, designers must perform a study to calculate each surface's Hinge Moment $(H)$. Then, the required Servo force can be determined by multiplying $(H)$ by the Servo's deflection rate and by the control surface's deflection rate. $H$ is obtained by multiplying the required Servo force by the arm that connects the Servo with the control surface, Equation 37.

$$
\begin{gathered}
H=\frac{1}{2} \rho V_{\infty} S_{C} C_{C o n t} C_{h i} \\
C_{h i}=\left(C_{h_{0}}+C_{h_{\alpha}} \alpha+C_{h_{\delta_{C}}} \delta_{C o n t}\right)
\end{gathered}
$$

$\left(S_{C}\right)$ refers to the reference control surface planform area to evaluate, and $\left(C_{C o n t}\right)$ is the chord of the control surface to evaluate. From Equation 38, $\left(C_{h i}\right)$ is the coefficient of the hinge moment, $(\alpha)$ is the maximum angle of attack of the aircraft in its flight envelope, $\left(C_{N_{o}}\right)$ is the coefficient of the hinge moment when the $\mathrm{AOA}=0^{\circ},\left(C_{h_{\alpha}} \alpha\right)$ is the slope of the curve of the coefficient of the hinge moment about the AOA and $\left(C_{h_{\delta_{C}}} \delta_{C o n t}\right)$ represents the change in the hinge moment with respect to the control surface deflection.

\subsection{Workflow diagrams}

What is described previously is summarized in workflow diagrams which are intended to help with the corresponding programming of these methodologies in a $\mathrm{C}++$ program. From Figure 6 to Figure 8 the workflows are shown.

\section{Elevator design methodology workflow diagram}

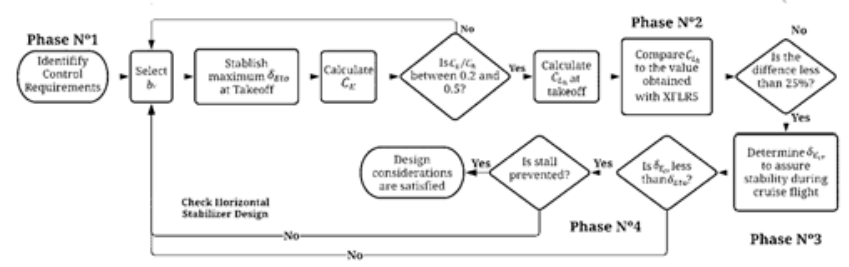

Figure 6 Elevator design methodology workflow diagram 


\section{Ailerons design methodology workflow diagram}

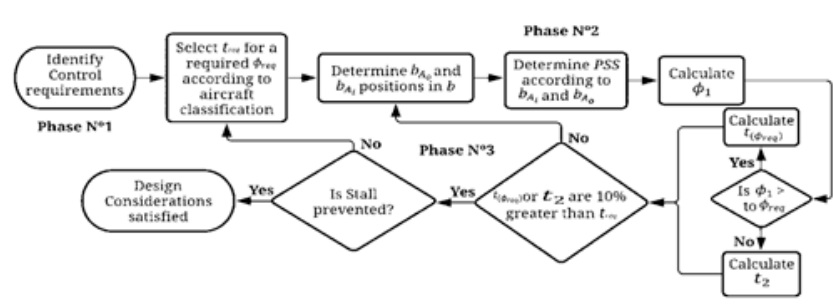

Figure 7 Ailerons design methodology workflow diagram

\section{Rudder design methodology workflow diagram}

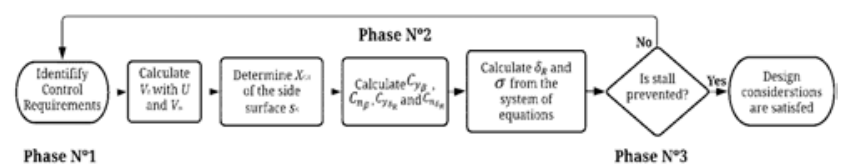

Figure 8 Rudder design methodology workflow diagram

\section{Result}

The use of the proposed methodology allows standardizing the design of the control surfaces in Micro Class prototypes of UNIMET SAE Aero Design. Reduction in time use regarding this design stage is considerable, allowing a more efficient use of resources available to finish the project within the deadlines.

\subsection{Aileron's design sensitivity analysis}

In the case of the latest aircraft design, the aileron's needed to assure a $30^{\circ}$ bank angle in $1.3 \mathrm{~s}$. For this requirement, a sensitivity analysis was performed by setting the aileron-to-wing chord ratio $\left(\frac{C_{A}}{C}\right)$ at $20 \%$ and the aileron's outboard position at $90 \%$ of the wing semi-span. Then, the aileron-to-wing span ratio was iterated until the requirements were met. Figure 9 shows the sensitivity analysis' optimal result within the operative boundaries suggested by designers.

Figure 10 shows the sensitivity analysis' optimal result for an aileron-to-wing chord ratio $\left(\frac{C_{A}}{C}\right)$ at $15 \%$, and the aileron's outboard position at $80 \%$ of the wing semi-span. The analyses aim to provide a visual tool to determine the design boundaries when varying the aileron's outboard position, the aileron-to-wing chord ratio and the aileron-to-wing span.

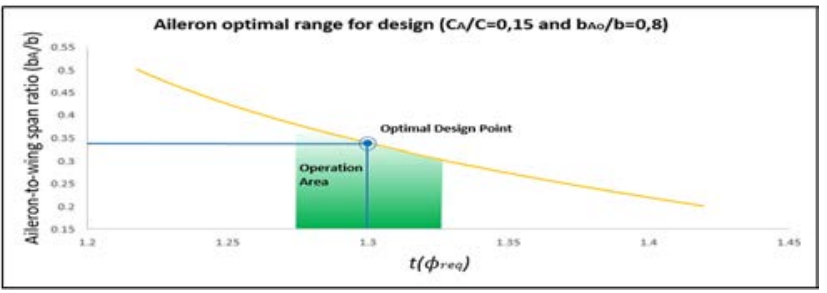

Figure 9 Sensitivity Analysis for a 20\% the aileron-to-wing chord ratio

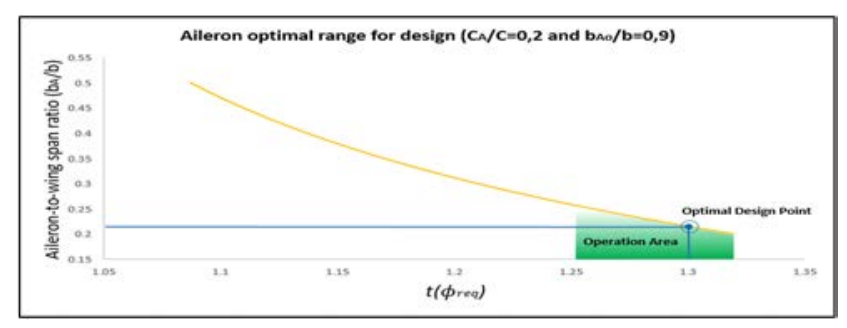

Figure 10 Sensitivity Analysis for a 20\% the aileron-to-wing chord ratio

\subsection{Weight analysis of the control systems}

Micro Class in SAE Aero Design demands, among other challenges, that the aeromodels have the least empty weight $\left(E_{w}\right)$ possible. Thereby, control systems' weight directly affects the design objectives. The application of the methodology allows reducing the size of the control surfaces dimensions and reduce the $\left(E_{w}\right)$ without sacrificing the control mission requirements. As a comparison, the relation between the total weight of control systems $\left(W_{\text {control }}\right)$ and $\left(E_{w}\right)$ of prototypes from 2018, 2019, and 2020 competitions is shown in Table 8. ( $\left.W_{\text {control }}\right)$ is the sum of the weights of structure and coating of Elevator, Rudder and Ailerons, as well as the servo motors that move each of these surfaces. The servo motors selection depends on the required torque to move the control surfaces [36].

Table 8 Control systems to aircraft's empty weight fraction [33],

\begin{tabular}{cccc}
\hline & $\mathbf{2 0 1 8}$ & $\mathbf{2 0 1 9}$ & $\mathbf{2 0 2 0}$ \\
\hline$E_{W}(g)$ & 327.3 & 341.8 & 405.5 \\
$W_{\text {control }}(g)$ & 20.8 & 15.5 & 13.8 \\
$\frac{W_{\text {control }}(g)}{E_{W}}$ & $6.4 \%$ & $4.5 \%$ & $3.4 \%$ \\
\hline
\end{tabular}

In 2018, the team designed control surfaces following recommended sizing from literature examples [36]. This approach led to oversizing the control surfaces. The following year, designers established control mission requirements for each surface and approached a preliminary version of the design methodology [37]. This helped reduce control surface size but did not satisfy adequate handling characteristics for the flight mission. 
In 2020, the proposed methodology helped reduce the $\frac{W_{\text {control }}}{E_{w}}(g)$ in $1.1 \%$ compared to the 2019 prototype. Therefore, designers are now able to distribute the spared weight in the selection of a more potent power plant and to manufacture a more robust structure to absorb landing stresses.

\section{Conclusions}

The proposed methodology has enabled the development of a sequence of stages in the process of design and optimization of control surfaces in prototypes of the Micro Class of Aero Design. Its application has allowed the reduction of the relation between control systems to aircraft's empty weight in circumstances with higher empty weight requirements. In addition, the methodology facilitates the performance of sensitivity analysis with design parameters until optimal results are obtained. It is recommended to adapt the methodology to model aircraft whose characteristics and mission are different from those required for the Micro category of the SAE Aero design competition. In the same sense, it is proposed to evaluate the methodology for the design of the rudder under critical conditions different from the landing and takeoff to crosswind, such as coordinated turn, adverse yaw and spin of the aircraft.

\section{Declaration of competing interest}

We declare that we have no significant competing interests, including financial or non-financial, professional, or personal interests interfering with the full and objective presentation of the work described in this manuscript.

\section{Acknowledgements}

The authors would like to thank the support provided by the School of Mechanical Engineering of the Universidad Metropolitana, Caracas - Venezuela, and the Faculty of Civil Industrial Engineering and Technology of the Universidad San Sebastián, Valdivia - Chile.

\section{Funding}

This work was supported by Fundación Académica José Abdala (FAJA) Universidad Metropolitana.

\section{Author contributions}

Rafael A. Márquez: Investigation, Formal analysis, Software, Methodology, Funding acquisition, Writing
- original draft. Miguel A. Martínez: Investigation, Formal analysis, Software, Methodology, Writing original draft, Funding acquisition. Manuel J. Martínez: Investigation, Writing - review \& editing, Methodology, Conceptualization, Supervision.

\section{References}

[1] About sae aero design series. SAE International. [Online]. Available: https://www.sae.org/attend/student-events/ sae-aero-design-knowledge/about

[2] "2020 collegiate design series. sae aero design rules," SAE Aero Design, Tech. Rep., 2020. [Online]. Available: http://www.saeaerodesign.com/cdsweb/gen/DownloadDocument. aspx?DocumentID=046e30f2-a5f2-462d-bc6b-261475056c2b

[3] K. A. Demir, H. Cicibas, and N. Arica, "Unmanned aerial vehicle domain: Areas of research," Defence Science Journal, vol. 65, no. 4, Jul. 4, 2015. [Online]. Available: https://n9.cl/pjhal

[4] L. D. Santos, G. Araújo, B. Souza, and A. Delon, "Use of remotely piloted aircraft in precision agriculture: a review," DYNA Revista de la Facultad de Minas de la Universidad Nacional de Colombia, vol. 86, no. 210, Sep. 2019. [Online]. Available: https: //revistas.unal.edu.co/index.php/dyna/article/view/74701/74208

[5] M. Fioriti and et al., "Multidisciplinary aircraft integration within a collaborative and distributed design framework using the agile paradign," Progress in Aerospace Sciences, vol. 119, no. 100648, Nov. 2020. [Online]. Available: https://doi.org/10.1016/j.paerosci.2020. 100648

[6] A. Kumar. (2010) Aircraft design. Cambridge University Press. [Online]. Available: https://n9.cl/ptsaw

[7] N. Cross. (2005) Engineering design methods. strategies for product design. John Wiley and Sons, Itd. [Online]. Available: https://fliphtml5.com/zroi/mnlp/basic

[8] C. Johansson, M. Derelöv, and J. Ölvander, "How to use an optimization based method capable of balancing safety, reliability, and weight in an aircraft design process," Nuclear Engineering and Technology, vol. 49, no. 2, Mar. 2017. [Online]. Available: https://doi.org/10.1016/j.net.2017.01.006

[9] G. Dimitriadis, "Aircraft desing lecture 9: Stability and control," Université de Liège. [Online]. Available: http://www.ltas-cm3.ulg. ac.be/AERO0023-1/ConceptionAeroStabilite.pdf

[10] N. Qin and et al., "Aerodynamic considerations of blended wing body aircraft," Progress in Aerospace Sciences, vol. 40, no. 6, Aug. 2004. [Online]. Available: https://doi.org/10.1016/j.paerosci.2004.08.001

[11] H. K. Fathy, J. A. Reyer, P. Y. Papalambros, and A. G. Ulsoy, "On the coupling between the plant and controller optimization problems," Proceedings of the American Control Conference, Arlington, VA, 2001. [Online]. Available: https://ieeexplore.ieee.org/ abstract/document/946008

[12] Y. Denieu, J. Bordeneuve, D. Alazard, C. Toussaint, and G. Taquin, "Integrated design of flight control surfaces and laws for new aircraft configurations," IFAC PapersOnLine, vol. 50, no. 1, Jul. 2017. [Online]. Available: https://doi.org/10.1016/j.ifacol.2017.08.2085

[13] L. L. Green and A. M. Spence, "Applications of computational methods for dynamic stability and control derivatives," in 42nd AIAA Aerospace Sciences Meeting and Exhibit, A. M. Paper, Ed. Reno, NV: ARC Aerospace Research Central, 2004, pp. 1-16. [Online]. Available: https://doi.org/10.2514/6.2004-377

[14] F. Nicolosi, D. Ciliberti, P. D. Vecchia, and S. Corcione, "Experimental analysis of aircraft directional control effectiveness," Aerospace Science and Technology, vol. 106, no. 106099, Nov. 2020. [Online]. Available: https://doi.org/10.1016/j.ast.2020.106099

[15] A. Rizzi, "Modeling and simulating aircraft stability and control the simsac project," Progress in Aerospace Sciences, vol. 47, no. 8, Nov. 2011. [Online]. Available: https://doi.org/10.1016/j.paerosci.2011. 08.004

[16] F. K. Owen and A. K. Owen, "Measurement and assessment of wind 
tunnel flow quality," Progress in Aerospace Sciences, vol. 44, no. 5, Jul. 2008. [Online]. Available: https://doi.org/10.1016/j.paerosci. 2008.04.002

[17] V. E. Gasparetto, M. R. Machado, and S. Carneiro, "Experimental modal analysis of an aircraft wing prototype for sae aerodesign competition," DYNA Revista de la Facultad de Minas de la Universidad Nacional de Colombia, vol. 87, no. 214, Sep. 2020. [Online]. Available: http://www.scielo.org.co/scielo.php?script=sci_arttext\& pid $=$ S0012-73532020000300100

[18] S. J. Stebbins, E. Loth, A. P. Broeren, and M. Potapczuk, "Review of computational methods for aerodynamic analysis of iced lifting surfaces," Progress in Aerospace Siences, vol. 111, no. 100583, Nov. 2019. [Online]. Available: https://doi.org/10.1016/j.paerosci.2019. 100583

[19] G. M. Quijada and P. J. Boschetti. (2015) Linear computational fluid dynamic analysis of dynamic ground effect of a wing in sink and flare maneuvers. American Institute of Aeronautics and Astronautics. [Online]. Available: https://doi.org/10.2514/6.2015-0518

[20] 0. González, G. Martínez, and C. A. Graciano, “Evaluación paramétrica de las principales variables geométricas en el diseño de un tren de aterrizaje para un avión no tripulado utilizando el método de los elementos finitos," Revista UIS Ingenierías, vol. 19, no. 2, Mar. 30, 2020. [Online]. Available: https://doi.org/10.18273/revuin.v19n2-2020017

[21] J. Slotnick and et al., "Cfd vision 2030 study: A path to revolutionary computational aerosciences," NASA, Tech. Rep., Mar. 2014. [Online]. Available: https://ntrs.nasa.gov/citations/20140003093

[22] A. Benaouali and S. Kachel, "Multidisciplinary design optimization of aircraft wing using commercial software integration," Aerospace Science and Technology, vol. 92, Sep. 2019. [Online]. Available: https://doi.org/10.1016/j.ast.2019.06.040

[23] André. (2020) Xftr5 general description. [Online]. Available: https: //sourceforge.net/projects/xflr5/files/

[24] "Federal aviation administration, department of transportation. part 23. airworthiness standards normal category airplanes," in Title 14. Aeronautics and Space. Electronic Code of Federal Regulations. [Online]. Available: https://www.ecfr.gov/cgi-bin/ text-idx?SID=2869bfb277872cfe179c9243991267f4\&mc=true\&tpl= /ecfrbrowse/Title14/14tab_02.tpl

[25] Mil-F-8785C Military Specification Flying Qualities of Piloted Airplanes, Department of the Air Force, 1969. [Online]. Available: https://www.abbottaerospace.com/downloads/ mil-f-8785c-flying-qualities- of-piloted-airplanes/

[26] (2016) Airplane flying handbook. U.S. Department of Transportation. Federal Aviation Administration. Oklahoma. [Online]. Available: https://n9.cl/54q0k
[27] M. H. Sadraey. (2013) Aircraft design. a systems engineering approach. John Wiley \& Sons. Ltd. [Online]. Available: https://www.wiley.com/en-ru/Aircraft+Design\%3A+A+ Systems+Engineering+Approach-p-9781119953401

[28] E. L. Houghton and P. W. Carpenter. (2003) Aerodynamics for engineering students. Butterworth-Heinemann. [Online]. Available: https://soaneemrana.org/onewebmedia/ Aerodynamics---Houghton\&Carpenter.pdf

[29] R. A. Ávila and V. A. Gómez. Universidad Metropolitana. Caracas, VEN. [Online]. Available: https://acortar.link/we9aq4

[30] D. P. Raymer. (1992) Aircraft design. a conceptual approach. American Institute of Aeronautics and Astronautics, Inc. [Online]. Available: https://acortar.link/YPHYX

[31] M. Sadraey and R. Colgren, "A systems engineering approach to the design of control surfaces for uavs," 45th AIAA Aerospace Sciences Meeting and Exhibit, Reno, NV, 2007. [Online]. Available: https://arc.aiaa.org/doi/10.2514/6.2007-660

[32] "Introduction to aircraft stability and control course notes for m\&ae 5070," Cornell University, Sibley School of Mechanical \& Aerospace Engineering, Ithaca, NY, 2011. [Online]. Available: https://courses.cit.cornell.edu/mae5070/Caughey_2011_04.pdf

[33] L. Marquez and et al., "2020 sae aero design east design report universidad metropolitana," Universidad Metropolitana, Caracas, VE, Tech. Rep., 2020. [Online]. Available: https://www.researchgate. net/publication/350567497_2020_SAE_AERO_DESIGN_EAST_ DESIGN REPORT UNIVERSIDAD METROPOLITANA

[34] C. Wolowicz and R. Yancey, "Lateral-directional aerodynamic characteristics of light, twin-engine, propeller driven airplanes," NASA, Washington, DC, Tech. Rep., Oct. 1972. [Online]. Available: https://ntrs.nasa.gov/citations/19730002289

[35] J. Grasmeyer, "Stability and control derivative estimation and engine-out analysis," Virginia Polytechnic Institute and State University, Blacksburg, VA, Tech. Rep., Jan. 1998. [Online]. Available: http://www.dept.aoe.vt.edu/ mason/Mason_f/LDstabdoc.pdf

[36] V. Viera and et al., "2018 sae aero design east design report universidad metropolitana," Universidad Metropolitana, Caracas, VE, Tech. Rep., 2018. [Online]. Available: https://www.researchgate. net/publication/350567515_2018_SAE_AERO_DESIGN_EAST_ DESIGN REPORT UNIVERSIDAD METROPOLITANA

[37] A. Aguilera and et al., "2019 sae aero design east design report universidad metropolitana," Universidad Metropolitana, Caracas, VE, Tech. Rep., 2019. [Online]. Available: https://www.researchgate. net/publication/350567399_2019_SAE_AERO_DESIGN_EAST_ DESIGN REPORT UNIVERSIDAD METROPOLITANA 